\title{
Synthesis of calcium antimonate nano-crystals by the 18th dynasty Egyptian glassmakers
}

\author{
S. Lahlil $\cdot$ I. Biron $\cdot$ M. Cotte $\cdot$ J. Susini $\cdot$ N. Menguy
}

Received: 9 October 2009 / Accepted: 13 October 2009 / Published online: 30 October 2009

(C) Springer-Verlag 2009

\begin{abstract}
During the 18th Egyptian dynasty (1570-1292 B.C.), opaque white, blue and turquoise glasses were opacified by calcium antimonate crystals dispersed in a vitreous matrix. The technological processes as well as the antimony sources used to manufacture these crystals remain unknown. Our results shed a new light on glassmaking history: contrary to what was thought, we demonstrate that Egyptian glassmakers did not use in situ crystallization but first synthesized calcium antimonate opacifiers, which do not exist in nature, and then added them to a glass. Furthermore, using transmission electron microscopy (TEM) for the first time in the study of Egyptian opaque glasses, we show that these opacifiers were nano-crystals. Prior to this research, such a process for glassmaking has not been suggested for any kind of ancient opaque glass production. Studying various preparation methods for calcium antimonate, we propose that Egyptian craftsmen could have produced $\mathrm{Ca}_{2} \mathrm{Sb}_{2} \mathrm{O}_{7}$ by using mixtures of $\mathrm{Sb}_{2} \mathrm{O}_{3}$ or $\mathrm{Sb}_{2} \mathrm{O}_{5}$ with calcium carbonates (atomic ratio $\mathrm{Sb} / \mathrm{Ca}=1$ ) heat treated between 1000 and $1100^{\circ} \mathrm{C}$. We developed an original strategy
\end{abstract}

\section{S. Lahlil $(\bowtie) \cdot$ I. Biron $\cdot$ M. Cotte}

C2RMF, Centre de Recherche et de Restauration des Musées de France, 14 quai François Mitterrand, Palais du Louvre, Porte des Lions, 75001 Paris, France

e-mail: sophia.lahlil@culture.gouv.fr

Fax: +33-140-202422

M. Cotte $\cdot$ J. Susini

ESRF, European Synchrotron Radiation Facility, 6 rue Jules

Horowitz, BP 220, 38043 Grenoble Cedex 9, France

\section{N. Menguy}

IMPMC, Institut de Minéralogie et de Physique des Milieux Condensés, Universités Paris 6 et 7, IPGP 140 rue Lourmel,

75015 Paris, France focused on the investigation of the crystals and the vitreous matrices using an appropriate suite of high-sensitivity and high-resolution micro- and nano-analytical techniques (scanning electron microscopy (SEM), X-ray diffraction (XRD), TEM). Synchrotron-based micro X-ray absorption near edge spectroscopy ( $\mu$-XANES) proved to be very well suited to the selective measure of the antimony oxidation state in the vitreous matrix. This work is the starting point for a complete reassessment not only of ancient Egyptian glass studies but more generally of high-temperature technologies used throughout antiquity.

PACS $81.05 . \mathrm{Kf} \cdot 07.78 .+\mathrm{s} \cdot 07.85 . \mathrm{Qe} \cdot 61.50 . \mathrm{f} \cdot \mathbf{8 1 . 1 0 . \mathrm { Fq }}$

\section{Introduction}

Glass first appeared in Mesopotamia around the middle of the 3rd millennium B.C. but the first real 'production' of glass objects took place in Egypt, during the 18th dynasty (1570-1292 B.C.). These objects are mainly opaque colored glass exhibiting high technical and aesthetic qualities (Fig. 1). They were dedicated to privileged people linked to the royal family and were used as perfume or cosmetic containers $[1,2]$. Most of these glasses are opacified by white crystals of calcium antimonate $\left(\mathrm{CaSb}_{2} \mathrm{O}_{6}\right.$ or $\left.\mathrm{Ca}_{2} \mathrm{Sb}_{2} \mathrm{O}_{7}\right)$ [3-5] reflecting and scattering light thanks to their random distribution, their index of refraction and a size of the order of the wavelength of visible light $[6,7]$. Among the different types of glass opacifiers used throughout history, antimonates have a predominant role as they are found from the origin of glass technology in Mesopotamia until modern times. They are consistently found in ancient Egyptian and Roman opaque glasses: evidence of an extensive use during antiquity [3-5, 8-10]. Despite being of prime interest for the 


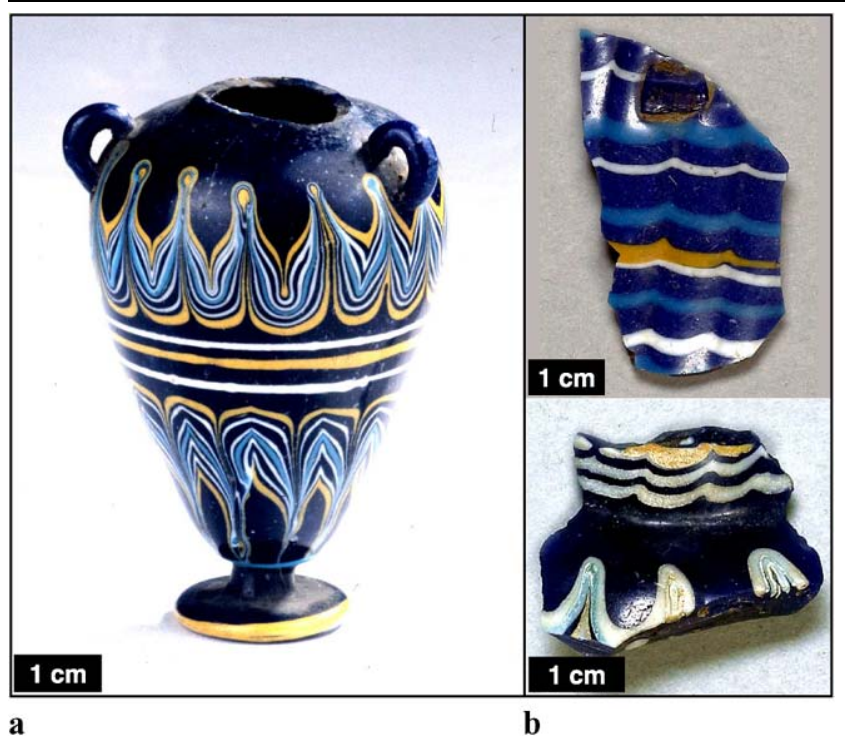

Fig. 1 Opaque colored glass of the 18th Egyptian dynasty. (a) Small amphorae (inventory number AF2622; (C) D. Bagault C2RMF). (b) Shards (inventory numbers: AF12707 and AF13175; (C) D. Vigears C2RMF). These objects come from the Egyptian Antiquities Department of the Louvre Museum

history of glassmaking, both the technology and provenance of the antimonates remain obscure. Consequently, this work aims to find the processes used to manufacture calcium antimonate opacified glasses in ancient Egypt.

Generally, glass opacification relies on two main processes. The first consists of the addition of natural or ex situ synthesized crystals to a translucent glass. The second relies on the introduction of antimony as an oxide or a sulphide into glass. It leads to the in situ crystallization of opacifying agents through the separation from the melt of calcium antimonate crystals. Other opacification processes generally derive from these two basic methods, like for example the addition of an opacifier-rich glass, called 'corpo' in Venice, to a translucent glass [11]. Recent studies based on chemical analyses and micro-structural observations favor in situ crystallization for ancient Egyptian opaque glass [4, 5]. However, experimental syntheses of opaque glass under controlled conditions, as well as selective analyses of both opacifying crystals and vitreous matrices, are indeed lacking. Contributing to an in-depth knowledge of Egyptian glass technology using a rigorous methodology is the key objective of this paper.

\section{Materials and methods}

For the first time, transmission electron microscopy (TEM) and synchrotron-based micro X-ray absorption near edge spectroscopy ( $\mu$-XANES) are used in the study of Egyptian opaque glasses. Both high-resolution analytical techniques proved to be very well suited respectively to the observation of small-size crystals and to the selective measure of the antimony oxidation state in the vitreous matrix. Furthermore, instead of limiting characterization to early glasses, we compare archaeological samples to reference glasses synthesized in the laboratory following the two main opacification processes mentioned above. Physical and chemical characteristics (elemental chemical composition, micro-structure, crystalline phases and oxidation state of antimony in the vitreous matrix) are measured in each archaeological and synthetic sample.

\subsection{Archaeological material}

Nine white, blue and turquoise opaque glasses from the 18th Egyptian dynasty from the Louvre Museum and from the British Museum are studied in this paper. These objects are fragments of vessel glasses (Fig. 1b). Samples $\left(0.2 \times 0.5 \mathrm{~cm}^{2}\right)$ were obtained from all the shards using a diamond saw, and were embedded in a polyvinyl resin block and polished using diamond pastes down to $0.25 \mu \mathrm{m}$.

\subsection{Syntheses of reference glasses}

In order to simplify the interpretation of the results, antimony compounds are introduced into a previously homogeneous synthesized glass rather than into the raw materials. Indeed, the process chosen allows us to limit the interferences between the antimony and the other compounds. Therefore, in a first step, a translucent soda-lime-silica glass with a composition very close to that of Egyptian samples is synthesized in Saint-Gobain Recherche. ${ }^{1}$

Reference glasses opacified by in situ crystallization are obtained by milling this glass with commercial products $\mathrm{Sb}_{2} \mathrm{~S}_{3}, \mathrm{Sb}_{2} \mathrm{O}_{3}, \mathrm{Sb}_{2} \mathrm{O}_{4}$ or $\mathrm{Sb}_{2} \mathrm{O}_{5} .^{2}$ These mixtures are fired at $1200^{\circ} \mathrm{C}$ for $1 \mathrm{~h}$ in a platinum crucible. A second melting is done after milling, in the same conditions, in order to homogenize the glass. The antimony concentration, the melting and heat-treatment temperatures, as well as the duration of heat treatment and cooling are monitored over a broad range of values $\left(\mathrm{Sb}_{2} \mathrm{~S}_{3}, \mathrm{Sb}_{2} \mathrm{O}_{3}\right.$ or $\mathrm{Sb}_{2} \mathrm{O}_{4}$ or $\mathrm{Sb}_{2} \mathrm{O}_{5}$ concentration $0.5-10 \mathrm{wt} \% ; T 700-1250^{\circ} \mathrm{C}, t 30 \mathrm{~min}-13$ days, quenching or 12-h cooling).

Reference glasses opacified by addition of crystals are obtained by milling the translucent soda-lime-silica glass

${ }^{1}$ Composition expressed in oxide wt $\%: \mathrm{Na}_{2} \mathrm{O} 14.2, \mathrm{MgO} 0.3, \mathrm{Al}_{2} \mathrm{O}_{3}$ 2.3, $\mathrm{SiO}_{2}$ 69.8, $\mathrm{SO}_{3}$ 0.4, $\mathrm{Cl} 0.4, \mathrm{~K}_{2} \mathrm{O} 0.8, \mathrm{CaO}$ 9.8, $\mathrm{MnO}$ 0.6, $\mathrm{Fe}_{2} \mathrm{O}_{3}$ 1.3.

${ }^{2}$ Antimony compound providers: $\mathrm{Sb}_{2} \mathrm{~S}_{3}$ : Kremer-Pigmente 10940, $\mathrm{Sb}_{2} \mathrm{O}_{3}$ : Acros Organics CAS 1309644, $\mathrm{Sb}_{2} \mathrm{O}_{5}$ : Aldrich CAS 1314609; $\mathrm{Sb}_{2} \mathrm{O}_{4}$ was obtained by heating $\mathrm{Sb}_{2} \mathrm{~S}_{3}$ at $500^{\circ} \mathrm{C}$ during $48 \mathrm{~h}$. 

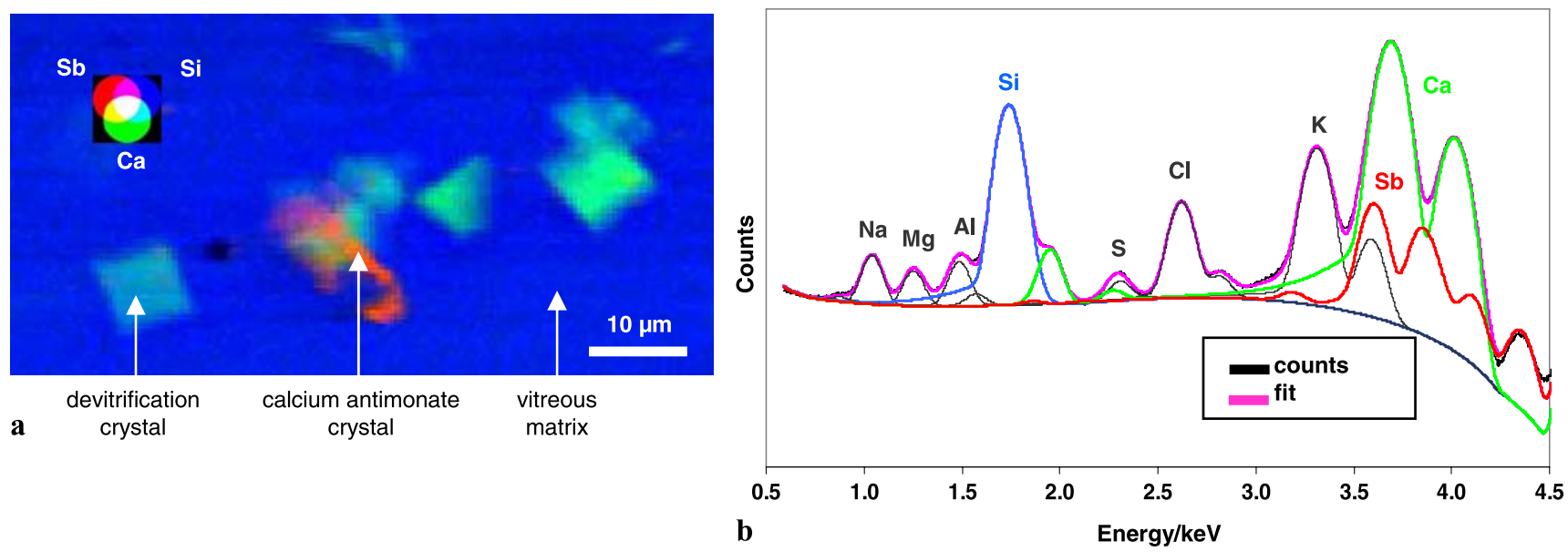

Fig. 2 Micro X-ray fluorescence ( $\mu$-XRF) analysis of a polished fragment of Egyptian glass (sample C). (a) $\mu$-XRF elemental maps of $\mathrm{Sb}($ red $), \mathrm{Ca}$ (green) and $\mathrm{Si}$ (blue). Map size $=72 \times 36 \mu \mathrm{m}^{2}$, pixel

size $=0.5 \times 0.5 \mu \mathrm{m}^{2}$ and probe size $=1.1 \times 0.3 \mu \mathrm{m}^{2}$. (b) Average $\mu$-XRF spectrum performed in the vitreous matrix and fitted with PyMca [15]

with $\mathrm{Ca}_{2} \mathrm{Sb}_{2} \mathrm{O}_{7}$ crystals. $^{3}$ These mixtures are fired at $1000^{\circ} \mathrm{C}$ for $1 \mathrm{~h}$ in a platinum crucible.

\subsection{Measurement set-up}

The samples are first observed by an optical microscope; then, the microstructure is determined using a scanning electron microscope (SEM; JEOL 840, Oxford Instruments, $20 \mathrm{kV}$ ). Backscattering imagery (BSE) is very well suited to the study of this type of material as the image contrast varies according to the atomic number $(Z)$. Therefore, calcium antimonate crystals appear white (high $Z$ ) in a grey soda-lime-silica vitreous matrix (low $Z$ ). Elemental compositions of vitreous matrices and crystals are determined using an energy-dispersive X-ray spectrometer (EDX) coupled with the SEM. A metallic cobalt sample is used for the calibration of the semi-quantitative analysis system. The ISIS software (Oxford) with the ZAF correction method is used for data processing. The results in weight oxides are normalized at $100 \%$.

In order to identify the main crystalline phases, micro $\mathrm{X}$-ray diffraction $(\mu$-XRD) measurements are carried out on each sample using equipment recently developed at the C2RMF [12]. The time measurements used are 5-20 min. A corundum sample $\left(\alpha-\mathrm{Al}_{2} \mathrm{O}_{3}\right)$ is used for the calibration of the geometrical system. The software FIT2D [13] allows us to transform the 2D images into standard XRD diagrams, and the Bruker-AXS EVA software is used to identify the crystalline phases.

A thin foil in a calcium antimonate aggregate of a white Egyptian glass is prepared using focused ion beam (FIB)

\footnotetext{
${ }^{3}$ The conditions of synthesis of calcium antimonate crystals are described in the section below 'Results and discussion'.
}

milling performed with a FEI FIB 200 microscope at the CP2M (University Paul Cezanne, Marseilles, France) with the FIB lift-out method [14]. A thin layer of platinum is deposited on the specimen in order to protect the sample during the milling process. The FIB system uses a Ga liquid metal ion source for milling. A $30-\mathrm{kV} \mathrm{Ga}+$ beam operating at $\sim 20 \mathrm{nA}$ excavated the glass from both sides of the Pt layer to a depth of $4 \mu \mathrm{m}$. Before removal of the thin section, the sample is further thinned to $\sim 80 \mathrm{~nm}$ with a glancing angle beam at much lower beam currents of $\sim 100$ pA. Finally, a line pattern is drawn with the ion beam along the side and bottom edges of the thin section allowing its removal. The $\sim 10 \mu \mathrm{m} \times 4 \mu \mathrm{m} \times 100 \mathrm{~nm}$ slide is transferred at room pressure with a micro-manipulator on to the membrane of a carbon-coated 200 mesh copper grid. TEM observations are carried out in the IMPMC on a JEOL $2100 \mathrm{~F}$ microscope operating at $200 \mathrm{kV}$, equipped with a field-emission gun, an ultra high resolution (UHR) pole piece and a Gatan US4000 CCD camera. Particle sizes are analyzed using standard software of electronic diffraction patterns (Gatan Digital Micrograph, Scion Image and CaRIne Crystallography).

Synchrotron-based micro X-ray absorption near edge spectroscopy ( $\mu$-XANES) analyses are carried out at the ID21 beamline at the ESRF (Grenoble, France). This technique has many assets for the study of calcium antimonate opacified glasses:

(1) This is a non-destructive method which can be performed directly on polished cross sections.

(2) It allows a high spatial sensitivity (beam size from less than $0.5 \mu \mathrm{m}$ to $200 \mu \mathrm{m}$ ). The beam size, reduced to $1.1 \times 0.3 \mu \mathrm{m}^{2}$ (horiz $\times$ vert) thanks to Fresnel zone plates [15], enables us to selectively measure the antimony oxidation state in the vitreous matrix, eliminating any interference from crystals (Fig. 2a). 
(3) It gives a high chemical sensitivity with both the direct identification of the antimony oxidation state and the concomitant analysis of the chemical elemental composition by micro X-ray fluorescence ( $\mu$-XRF). Indeed, the beam energy is determined with a resolution of $0.5 \mathrm{eV}$ thanks to a fixed-exit, double-crystal Si(111) mono-

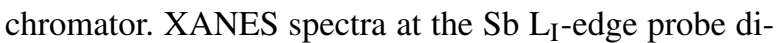
rectly the $\mathrm{Sb}$ oxidation state since the white line energy position for $\mathrm{Sb}^{\mathrm{III}}$ and $\mathrm{Sb}^{\mathrm{V}}$ compounds varies by $4.5 \mathrm{eV}$ [16]. The micro-fluorescence signal is collected using an HPGe solid-state energy-dispersive detector [17]. X-ray fluorescence spectra are fitted with PyMca [15] (Fig. 2b).

\section{Results and discussion}

Bulk elemental analyses on both crystals and vitreous matrices were performed by energy-dispersive X-ray spectrometry (EDX) on nine white, blue and turquoise opaque glasses from the 18th Egyptian dynasty from the Louvre Museum and from the British Museum. These results show that all the samples are plant-ash-based soda-lime-silica glasses ( $\mathrm{MgO}$ and $\mathrm{K}_{2} \mathrm{O}>1 \mathrm{wt} \%$ ) (Table 1). The amounts of calcium $(\mathrm{CaO} 7.2-12.7 \mathrm{wt} \%)$ and antimony $\left(\mathrm{Sb}_{2} \mathrm{O}_{3}\right.$ 0.4-3.5 wt\%), as well as the nature of the colorants used (cobalt for dark blue and copper for turquoise glasses), are consistent with previous measurements in opaque glass of the same period $[1,4,5,18]$ (Table 1). The white color of calcium antimonate crystals induces white glasses with colorless vitreous matrices, and induces brightened blue and turquoise glasses with colored matrices.

In ancient Egyptian glasses, we identify both $\mathrm{Ca}_{2} \mathrm{Sb}_{2} \mathrm{O}_{7}$ with an orthorhombic structure and $x \mathrm{Na}_{2} \mathrm{O}-y \mathrm{CaO}-z \mathrm{SiO}_{2}$ crystals (combeite, wollastonite, devitrite) (Figs. 2a and 3a). These latter are characteristic of the devitrification process by which glassy substances change their structure into that of crystalline solids of close composition. The crystals observed are typical of the devitrification of soda-lime-silica vitreous matrices between 750 and $1200^{\circ} \mathrm{C}$ [19, 20], demonstrating that Egyptian glasses were fired in such a range of temperature. Previous archaeological and experimental studies agree that the ancient Egyptian glass melting temperature lies below $1200^{\circ} \mathrm{C}$ [21-23]. The same crystalline phases are observed in a glass we synthesized by adding $\mathrm{Ca}_{2} \mathrm{Sb}_{2} \mathrm{O}_{7}$ crystals followed by a heat treatment at $900^{\circ} \mathrm{C}$ for $14 \mathrm{~h}$. Because of their size and their refractive index, which are very close to the vitreous matrices, these devitrification crystals do not contribute significantly to the glass opacification.

In the Egyptian glasses, calcium antimonate opacifiers form abundant aggregates of various rosary shapes and sizes (Fig. 3b). They have a rather heterogeneous distribution within the vitreous matrix (Fig. 3c). TEM observations, performed on a thin foil prepared from a calcium antimonate aggregate using focused ion beam (FIB) milling, show that the crystal sizes in aggregates have about $50-\mathrm{nm}$ length. Their arrangement is very compact and they correspond to orthorhombic $\mathrm{Ca}_{2} \mathrm{Sb}_{2} \mathrm{O}_{7}$ (Fig. 3d). These properties are not compatible with in situ crystallization, where nucleation of the crystals occurs randomly or at preferen-

Table 1 Bulk elemental compositions of opaque blue, white and turquoise Egyptian glasses of the 18th dynasty from the Louvre Museum and from the British Museum. Analyses were performed by EDX (expressed in oxide wt\%). Standard deviations are indicated in italics (average of five measurements). Each sample is labeled by a letter from 'A' to 'I'

\begin{tabular}{|c|c|c|c|c|c|c|c|c|c|c|c|c|c|c|c|c|c|c|}
\hline \multirow[b]{3}{*}{$\mathrm{Na}_{2} \mathrm{O}$} & \multicolumn{10}{|c|}{ Blue glasses } & \multicolumn{4}{|c|}{ White glasses } & \multicolumn{4}{|c|}{ Turquoise glasses } \\
\hline & \multicolumn{2}{|c|}{ Sample A } & \multicolumn{2}{|c|}{ Sample B } & \multicolumn{2}{|c|}{ Sample C } & \multicolumn{2}{|c|}{ Sample D } & \multicolumn{2}{|c|}{ Sample E } & \multicolumn{2}{|c|}{ Sample F } & \multicolumn{2}{|c|}{ Sample G } & \multicolumn{2}{|c|}{ Sample H } & \multicolumn{2}{|c|}{ Sample I } \\
\hline & 17.2 & 0.7 & 14.7 & 0.2 & 16.3 & 0.2 & 16.5 & 0.7 & 14.2 & 0.4 & 14.7 & 0.7 & 13.7 & 0.4 & 11.1 & 0.3 & 15.2 & 0.3 \\
\hline $\mathrm{MgO}$ & 4.0 & 0.4 & 4.0 & 0.1 & 4.3 & 0.0 & 4.0 & 0.2 & 4.3 & 0.2 & 3.3 & 0.2 & 3.2 & 0.2 & 3.0 & 0.0 & 4.4 & 0.3 \\
\hline $\mathrm{Al}_{2} \mathrm{O}_{3}$ & 3.9 & 0.3 & 2.6 & 0.1 & 2.4 & 0.1 & 2.8 & 0.3 & 1.0 & 0.2 & 0.5 & 0.3 & 0.2 & 0.5 & 0.3 & 0.2 & 0.9 & 0.8 \\
\hline $\mathrm{SiO}_{2}$ & 62.0 & 1.4 & 63.3 & 0.7 & 63.9 & 0.5 & 58.0 & 1.0 & 65.9 & 0.8 & 63.3 & 0.5 & 63.7 & 0.8 & 65.7 & 0.7 & 61.2 & 1.2 \\
\hline $\mathrm{SO}_{3}$ & 0.8 & 0.2 & 0.3 & 0.1 & 0.3 & 0.1 & 0.4 & 0.2 & 0.5 & 0.2 & 0.4 & 0.1 & 0.5 & 0.0 & 0.4 & 0.2 & 0.5 & 0.2 \\
\hline $\mathrm{Cl}$ & 1.5 & 0.1 & 0.7 & 0.2 & 0.9 & 0.0 & 0.6 & 0.1 & 1.0 & 0.2 & 0.9 & 0.1 & 0.9 & 0.3 & 0.6 & 0.2 & 0.7 & 0.1 \\
\hline $\mathrm{K}_{2} \mathrm{O}$ & 0.6 & 0.1 & 0.8 & 0.0 & 1.3 & 0.1 & 2.0 & 0.2 & 1.4 & 0.3 & 2.2 & 0.3 & 2.5 & 0.1 & 2.3 & 0.1 & 3.1 & 0.1 \\
\hline $\mathrm{CaO}$ & 7.2 & 0.7 & 10.9 & 0.3 & 8.5 & 0.1 & 12.3 & 1.2 & 10.2 & 0.3 & 10.9 & 0.6 & 11.2 & 0.8 & 12.7 & 0.1 & 10.6 & 1.1 \\
\hline $\mathrm{TiO}_{2}$ & 0.1 & 0.1 & 0.1 & 0.1 & 0.2 & 0.1 & 0.0 & 0.0 & 0.1 & 0.2 & 0.2 & 0.1 & 0.0 & 0.0 & 0.0 & 0.2 & 0.0 & 0.0 \\
\hline $\mathrm{MnO}$ & 0.5 & 0.1 & 0.3 & 0.1 & 0.2 & 0.1 & 0.6 & 0.1 & 0.2 & 0.1 & 0.1 & 0.1 & 0.1 & 0.1 & 0.0 & 0.1 & 0.1 & 0.1 \\
\hline $\mathrm{Fe}_{2} \mathrm{O}_{3}$ & 0.6 & 0.2 & 0.9 & 0.1 & 1.2 & 0.2 & 0.4 & 0.2 & 0.7 & 0.2 & 0.4 & 0.1 & 0.4 & 0.2 & 0.2 & 0.2 & 0.8 & 0.3 \\
\hline $\mathrm{CoO}$ & 0.5 & 0.1 & 0.3 & 0.2 & 0.2 & 0.2 & 0.1 & 0.1 & 0.1 & 0.1 & 0.1 & 0.1 & 0.0 & 0.0 & 0.0 & 0.0 & 0.2 & 0.2 \\
\hline $\mathrm{CuO}$ & 0.2 & 0.2 & 0.4 & 0.1 & 0.1 & 0.1 & 0.4 & 0.2 & 0.3 & 0.4 & 0.2 & 0.1 & 0.2 & 0.3 & 1.3 & 0.2 & 0.9 & 0.5 \\
\hline $\mathrm{Sb}_{2} \mathrm{O}_{3}$ & 0.9 & 0.4 & 0.5 & 0.4 & 0.4 & 0.4 & 1.7 & 0.5 & 0.5 & 0.6 & 2.9 & 0.4 & 3.5 & 0.1 & 2.6 & 0.4 & 1.7 & 0.3 \\
\hline
\end{tabular}



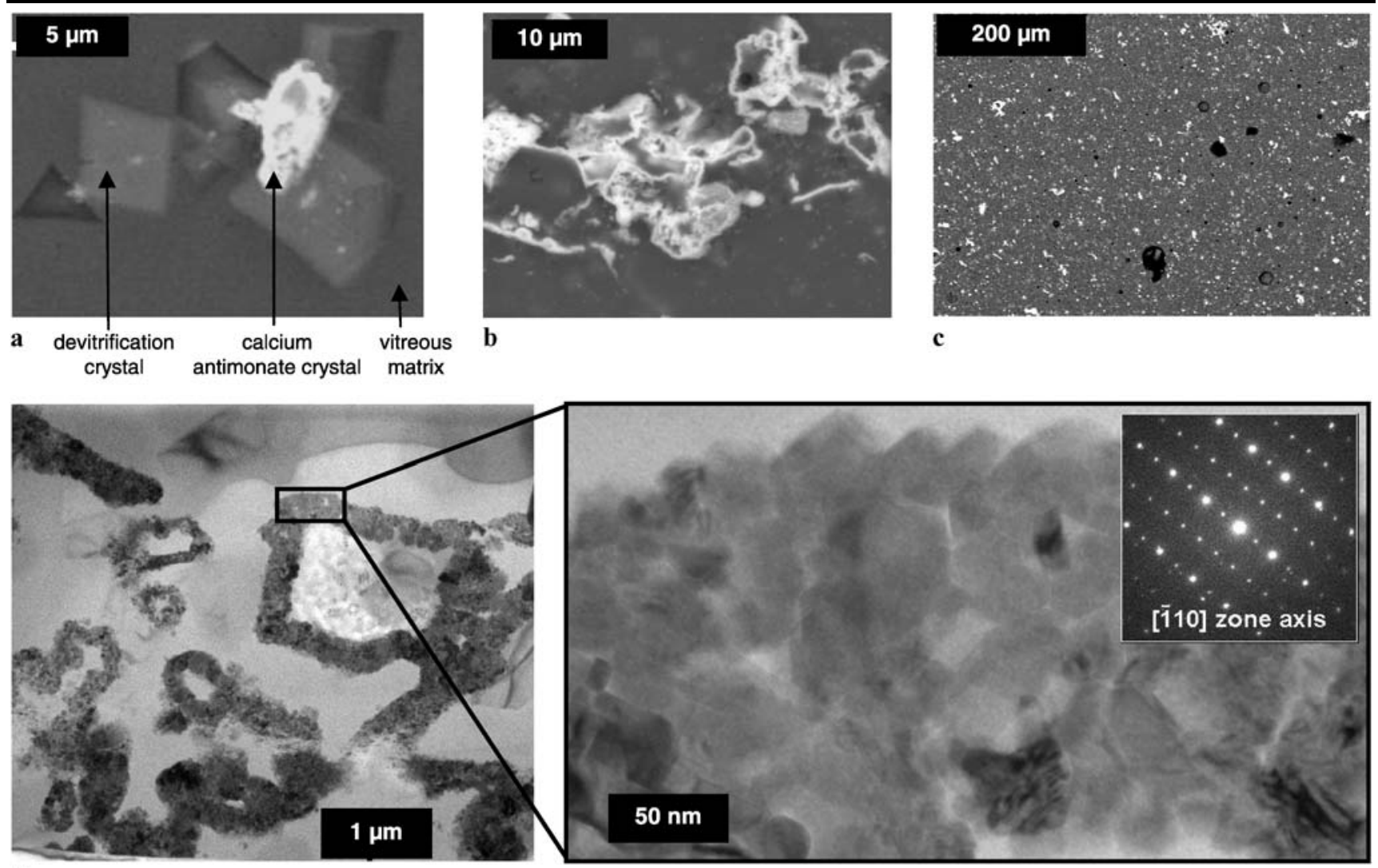

d

Fig. 3 Images of polished fragments of opaque Egyptian glasses. (a) SEM-BSE image evidencing calcium antimonates and geometrical devitrification crystals $\left(x \mathrm{Na}_{2} \mathrm{O}-y \mathrm{CaO}-z \mathrm{SiO}_{2}\right)$ (sample C). (b) SEMBSE images of an aggregate of calcium antimonate opacifiers dispersed in the vitreous matrix (sample F). (c) SEM-BSE images of

tial nucleation sites in the vitreous matrix [24]. Indeed, in all the in situ opacified glasses synthesized, we observe mainly isolated crystals or crystals around bubbles, and sometimes aggregates resulting from poorly dissolved antimony (Fig. 4a). Moreover, in these cases, calcium antimonates are polygonal crystals with average sizes greater than $1 \mu \mathrm{m}$ (Fig. 4a), indicating that the kinetics of crystallization are relatively fast. Furthermore, in these experimental glasses, both calcium antimonate phases crystallize in such a way that $\mathrm{CaSb}_{2} \mathrm{O}_{6}$ is kinetically favored, although $\mathrm{Ca}_{2} \mathrm{Sb}_{2} \mathrm{O}_{7}$ is thermodynamically stable. These latter nucleate and grow at the expense of $\mathrm{CaSb}_{2} \mathrm{O}_{6}$. Consequently, the in situ process implies that when $\mathrm{Ca}_{2} \mathrm{Sb}_{2} \mathrm{O}_{7}$ is the major phase obtained, crystals are not nano-metric. Therefore, in ancient Egyptian glasses, the predominance of submicronic $\mathrm{Ca}_{2} \mathrm{Sb}_{2} \mathrm{O}_{7}$ crystals organized in compact rosary shapes confirms that in situ crystallization had not occurred. On the contrary, in experimental glasses opacified by addition to a translucent glass of preliminary ex situ synthesized $\mathrm{Ca}_{2} \mathrm{Sb}_{2} \mathrm{O}_{7}$ crystals, both a predominant crystalline phase, $\mathrm{Ca}_{2} \mathrm{Sb}_{2} \mathrm{O}_{7}$, and micro-structures similar to Egyptian the general micro-structure (sample F). (d) TEM images of calcium antimonate nano-crystals forming an aggregate. In the inset, a [-110] zone axis electron diffraction pattern of a $\mathrm{Ca}_{2} \mathrm{Sb}_{2} \mathrm{O}_{7}$ nano-crystal is shown (orthorhombic structure) (sample F)

samples are observed (Fig. 4b), indicating that this process could have been used by Egyptian glassmakers. In such a process, the nature and the structure of the crystals remain the same after their addition to the soda-lime-silica glass. Although it is not excluded that part of these added crystals have dissolved and recrystallized in the matrix, the microstructure proves to be an efficient criterion to distinguish the in situ crystallization opacification process from the addition of crystals.

To confirm the preliminary hypothesis of an addition of crystals, we show that the oxidation state of antimony in the vitreous matrices is another indicator of the opacification process employed. Indeed, this parameter strongly depends upon the glassmaking conditions (chemical composition, temperature, atmosphere and so on) $[25,26]$. It is assumed to have a direct influence on calcium antimonate crystallization. Although the amounts of antimony in the vitreous matrices are very low, the oxidation state of this element was measured successfully in some samples. We have first verified with reference powders that antimony is exclusively $\mathrm{Sb}^{\mathrm{V}}$ in both $\mathrm{Ca}_{2} \mathrm{Sb}_{2} \mathrm{O}_{7}$ and $\mathrm{CaSb}_{2} \mathrm{O}_{6}$ crystals. 

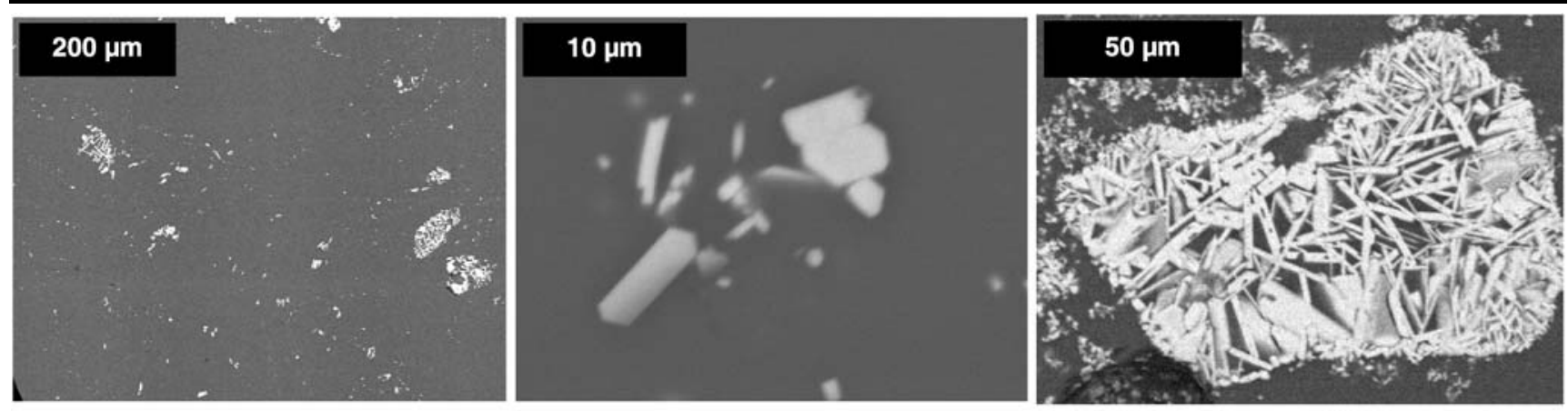

a
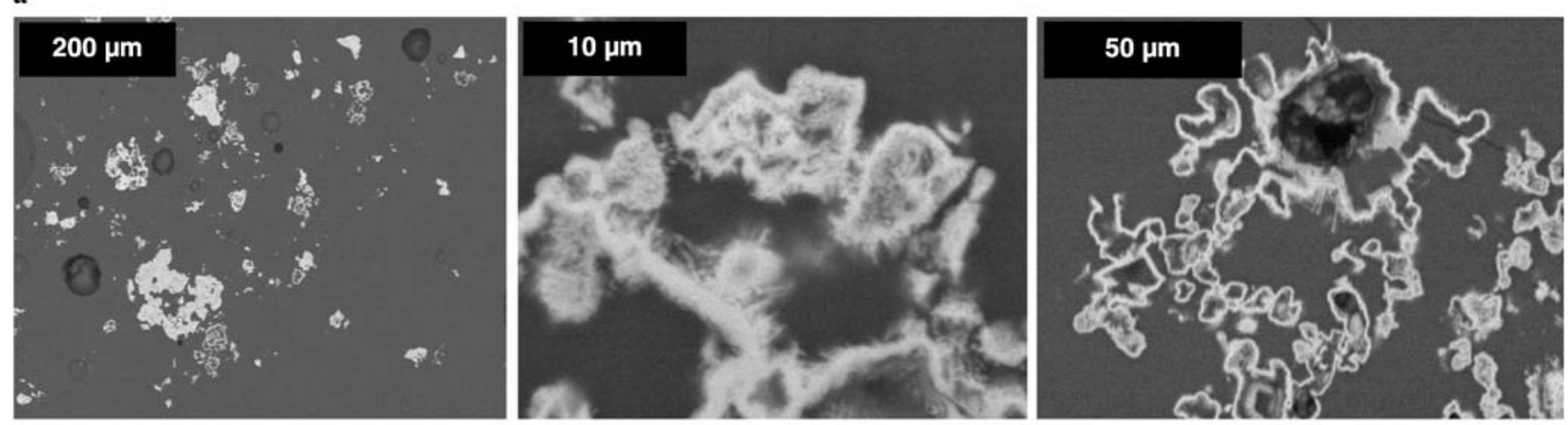

b

Fig. 4 SEM-BSE images of experimental opacified glasses. (a) General microstructure and details showing polygonal crystals isolated or in aggregates obtained by in situ crystallization (10 wt \% of $\mathrm{Sb}_{2} \mathrm{O}_{4}$ introduced in a translucent soda-lime-silica glass twice melted for $1 \mathrm{~h}$ at $1200^{\circ} \mathrm{C}$ ); (b) general microstructure and details showing small crystals forming aggregates of rosary shapes obtained by addition of $\mathrm{Ca}_{2} \mathrm{Sb}_{2} \mathrm{O}_{7}$ opacifiers $\left(10 \mathrm{wt} \% \mathrm{Ca}_{2} \mathrm{Sb}_{2} \mathrm{O}_{7}\right.$ introduced in a translucent soda-lime-silica glass melted at $1000^{\circ} \mathrm{C}$ for $1 \mathrm{~h}$ )

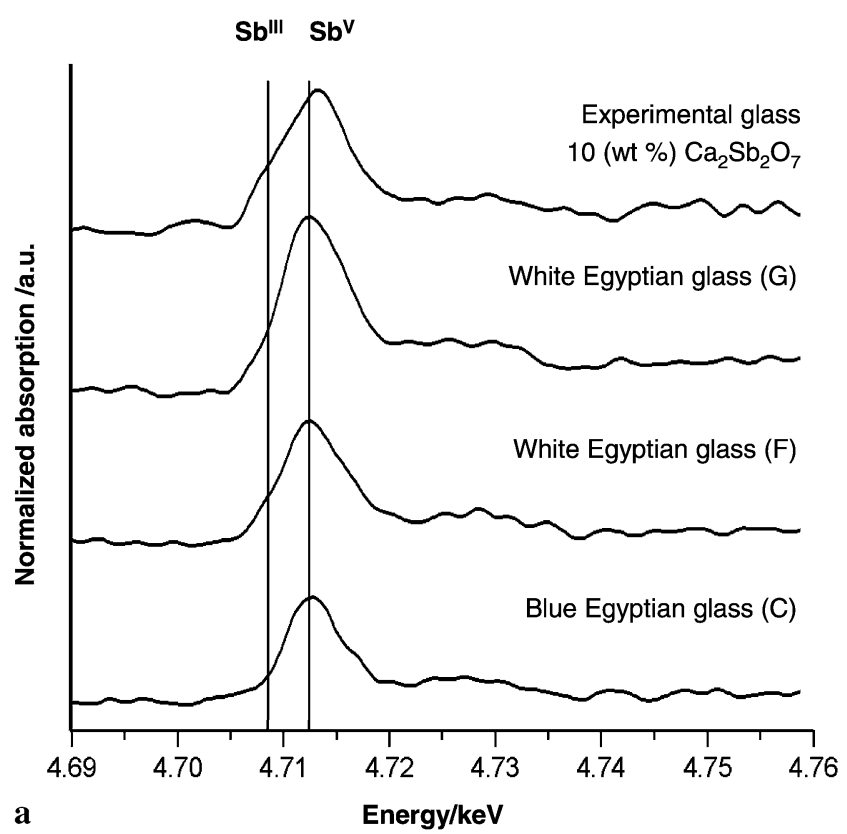

Fig. $5 \mu$-XANES spectra at the $\mathrm{Sb}_{\mathrm{I}}$-edge performed in the vitreous matrices (average of five measurements). (a) Archaeological Egyptian white and blue glasses (each sample is labeled with a letter) and experimental glass opacified by addition of $10 \mathrm{wt} \% \mathrm{Ca}_{2} \mathrm{Sb}_{2} \mathrm{O}_{7}$ to a translu-

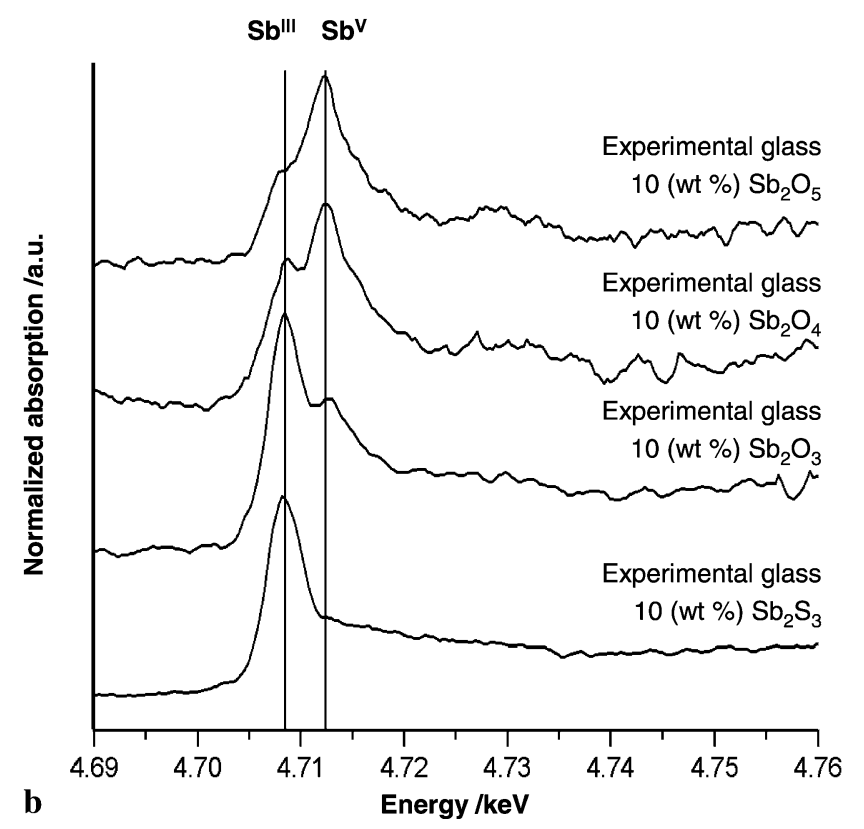

cent glass. (b) Experimental glass opacified by in situ crystallization from different antimony sources (10 wt $\% \mathrm{Sb}_{2} \mathrm{~S}_{3}, \mathrm{Sb}_{2} \mathrm{O}_{3}, \mathrm{Sb}_{2} \mathrm{O}_{4}$ and $\left.\mathrm{Sb}_{2} \mathrm{O}_{5}\right)$ 
When calcium antimonates are added into a glass, the crystals dissolve in the vitreous matrix during the glass melting in such a way that the chemical environment and the oxidation state of antimony remain the same. In experimental glasses opacified by addition of calcium antimonate crystals, a unique peak indicative of the presence of $\mathrm{Sb}^{\mathrm{V}}$ is displayed (Fig. 5a). Analogous $\mu$-XANES spectra are obtained in the vitreous matrix of the three different colored Egyptian glasses analyzed (Fig. 5a), indicating that a similar opacification process is used. The predominant presence of $\mathrm{Sb}^{\mathrm{V}}$ within all the archaeological samples further demonstrates the use of very similar procedures by Egyptian glassmakers. A different behavior of the antimony in the vitreous matrix is observed when antimony compounds such as $\mathrm{Sb}_{2} \mathrm{~S}_{3}, \mathrm{Sb}_{2} \mathrm{O}_{3}$, $\mathrm{Sb}_{2} \mathrm{O}_{4}$ or $\mathrm{Sb}_{2} \mathrm{O}_{5}$ are directly introduced into the glass to induce the in situ crystallization. In this case, either $\mathrm{Sb}^{\mathrm{III}}$ alone or a mixture of $\mathrm{Sb}^{\mathrm{III}}$ and $\mathrm{Sb}^{\mathrm{V}}$ are found (Fig. 5b) [24]. Therefore, the oxidation state of antimony in the vitreous matrix appears to be an efficient criterion to distinguish the addition of calcium antimonate crystals into a glass from the in situ crystallization. Our experiments show that this statement is only valid for temperatures below $1200^{\circ} \mathrm{C}$, which is a range of temperature consistent with ancient glass technology [21-23].

\section{Conclusions}

Our results on the microstructure, the crystalline phases and the antimony oxidation state not only refute the assertion that the 18th Egyptian dynasty glasses were opacified by in situ crystallization, but also demonstrate that they were made by the addition of crystals into a glass. The use of such a process has a major consequence: as $\mathrm{Ca}_{2} \mathrm{Sb}_{2} \mathrm{O}_{7}$ crystals do not exist in nature [27, 28], it implies that Egyptian glassmakers managed to synthesize the opacifiers before their addition to a translucent glass. These findings provide further evidence for the sophisticated chemistry and the remarkable know-how of this civilization. For now, Egyptian blue and green pigments (calcium copper silicates) were the only high-temperature compounds known to have been synthesized in this period [29]. Consequently, these results raise new questions on the pyrotechnical processes used by Egyptian glassmakers and on the knowledge possessed by these craftsmen.

In order to understand the procedures employed by ancient Egyptians to synthesize calcium antimonates, we have tested the conditions of preparation of $\mathrm{Ca}_{2} \mathrm{Sb}_{2} \mathrm{O}_{7}$ crystals. Various powdered mixtures of calcium carbonates and antimony compounds $\left(\mathrm{Sb}_{2} \mathrm{~S}_{3}, \mathrm{Sb}_{2} \mathrm{O}_{3}, \mathrm{Sb}_{2} \mathrm{O}_{4}\right.$ or $\left.\mathrm{Sb}_{2} \mathrm{O}_{5}\right)$ were fired between 700 and $1100^{\circ} \mathrm{C}$ for $1 \mathrm{~h}$ or $18 \mathrm{~h}$. The nature, the crystallographic structure and the oxidation state of antimony were investigated on the crystals obtained.
Our results indicate that $\mathrm{Ca}_{2} \mathrm{Sb}_{2} \mathrm{O}_{7}$ phase preferably crystallizes between 1000 and $1100^{\circ} \mathrm{C}$ after $1 \mathrm{~h}$, when $\mathrm{Sb}_{2} \mathrm{O}_{3}$ or $\mathrm{Sb}_{2} \mathrm{O}_{5}$ are introduced in the raw materials such that the atomic ratio $\mathrm{Sb} / \mathrm{Ca}$ is $1 .^{4}$ Below $1000^{\circ} \mathrm{C}$, a mixture of $\mathrm{CaSb}_{2} \mathrm{O}_{6}$ and $\mathrm{Ca}_{2} \mathrm{Sb}_{2} \mathrm{O}_{7}$ is produced, as well as other phases not observed in Egyptian glass. When the ratio $\mathrm{Sb} / \mathrm{Ca}$ is 2, the formation of $\mathrm{CaSb}_{2} \mathrm{O}_{6}$ is mainly induced, which is in agreement with previous studies [30-32]. Considering that specific conditions are required to produce $\mathrm{Ca}_{2} \mathrm{Sb}_{2} \mathrm{O}_{7}$ crystals $\left(\mathrm{Sb} / \mathrm{Ca}=1, \mathrm{Sb}_{2} \mathrm{O}_{3}\right.$ or $\left.\mathrm{Sb}_{2} \mathrm{O}_{5}\right)$ and that the timetemperature ranges are plausible for the period considered $\left(1000-1100^{\circ} \mathrm{C}, 1 \mathrm{~h}\right)$, we propose that very close procedures were used in Egypt during the 2nd millennium B.C. to obtain the glass opacifiers. These results further emphasize the problem of the choice of antimony products at that time. Currently, natural $\left(\mathrm{Sb}_{2} \mathrm{~S}_{3}\right)$ or roasted stibnite $\left(\mathrm{Sb}_{2} \mathrm{O}_{3}\right.$, $\mathrm{Sb}_{2} \mathrm{O}_{4}$ ) and metallic antimony are thought to be the main sources of antimony available during antiquity [3-5]. Our results suggest that stibnite could have been roasted under controlled conditions entailing the formation of $\mathrm{Sb}_{2} \mathrm{O}_{3}$ $\left(\sim 595^{\circ} \mathrm{C}\right)$ [33], which was used for the ex situ synthesis of calcium antimonate crystals. The use of such raw materials and of such a process sheds a new light on the history of ancient Egypt pyrotechnology. We believe that this work is the starting point for a complete reassessment not only of ancient Egyptian glass studies but more generally of hightemperature technologies used throughout antiquity.

Acknowledgements The authors thank C. Naffah and M. Menu for support in the laboratory of the Centre de Recherche et de Restauration des Musées de France (C2RMF (UMR 171)), G. Pierrat-Bonnefois of the Egyptian Antiquities Department of the Louvre Museum and I.C. Freestone of Cardiff University for making samples available to us, M.H. Chopinet (Saint-Gobain Recherche, SGR) for discussions and technical assistance and E. Laval (C2RMF), C. Dominici (Centre Pluridisciplinaire de Microscopie Electronique et de Microanalyse, C2PM), L. Cormier, G. Morin and Q. Dermigny (Institut de Minéralogie et de Physique des Milieux Condensés, IMPMC) for technical assistance. The authors also thank Y. Adda and P. Lehuédé for critical discussions and comments on the manuscript and A. Heuer, P. Walter and R. Pillay (C2RMF) for reading the manuscript. The $\mu$-XANES analyses were funded by grants from ESRF (experiment EC-281).

\section{References}

1. A.J. Shortland, Vitreous Materials at Amarna, BAR Int. Ser. vol. 827 (Archaeopress Pigments, Oxford, 2000)

2. P.T. Nicholson, J. Henderson, in Ancient Egyptian Materials and Technology, ed. by P.T. Nicholson, I. Shaw (Cambridge University Press, Cambridge, 2000), pp. 195-205

3. W.E.S. Turner, H.P. Rooksby, Glastech. Ber. 32K, 17 (1959)

4. A.J. Shortland, Archaeometry 44(4), 517 (2002)

5. J.L. Mass, M.T. Wypyski, R.E. Stone, Mater. Res. Soc. Bull. 26, 38 (2001)

${ }^{4} \mathrm{Ca}_{2} \mathrm{Sb}_{2} \mathrm{O}_{7}$ crystals remain stable at least until $1200^{\circ} \mathrm{C}$ (thermogravimetric measurements). 
6. H. Scholze, Glass, Nature, Structure and Properties (Springer, New York, 1991)

7. J. Barton, C. Guillemet, Le Verre, Science et Technologie (EDP Sciences, Les Ulis, 2005)

8. J.L. Mass, R.E. Stone, M.T. Wypyski, Mater. Res. Soc. Symp. Proc. 462, 193 (1997)

9. M. Tite, T. Pradell, A.J. Shortland, Archaeometry 50(1), 67 (2008)

10. S. Lahlil, I. Biron, L. Galoisy, G. Morin, Appl. Phys. A, Mater. 92(1), 109 (2008)

11. C. Moretti, S. Hreglich, Riv. Staz. Sper. Vetro 35(5), 28 (2005)

12. L. de Viguerie, L. Beck, J. Salomon, L. Pichon, Ph. Walter, Anal. Chem. doi:10.1021/ac901141v (2009)

13. A.P. Hammersley, C. Riekel, Synchrotron Radiat. News 2, 24 (1989)

14. K. Benzerara, N. Menguy, N.R. Banerjee, T. Tyliszczak, G.E. Brown Jr., F. Guyot, Earth Planet. Sci. Lett. 260, 187 (2007)

15. V.A. Solé, E. Papillon, M. Cotte, Ph. Walter, J. Susini, Spectrochim. Acta B 62(1), 63 (2007)

16. J. Dik, K. Janssens, G. Van der Snickt, L. van der Loeff, K. Rickers, M. Cotte, Anal. Chem. 80(16), 6436 (2008)

17. J. Susini, M. Salomé, B. Fayard, R. Ortega, B. Kaulich, Surf. Rev. Lett. 9, 203 (2002)

18. I. Biron, G. Pierrat-Bonnefois, Techne 15, 30 (2002)

19. G.W. Morey, J. Am. Ceram. Soc. 13(10), 683 (1930)

20. J.H. Simmons, D.R. Uhlmann, G.H. Beall (eds.), Advances in Ceramics, Nucleation and Crystallization in Glasses, vol. 4 (The American Ceramic Society, Ohio, 1981)
21. P.T.J. Nicholson, Glass Stud. 37, 11 (1995)

22. K. Heide, E. Hartman, K. Gert, H.G. Wiedemann, Thermochim. Acta 365(1-2), 147 (2000)

23. Th. Rehren, J. Glass Stud. 37, 13 (2000)

24. Lahlil et al., New insight on the in situ crystallization of calcium antimonate opacified glass during the Roman period. Appl. Phys. A, Mater. (2009, to be published)

25. C. Russel, E. Freude, Phys. Chem. Glasses 30(2), 62 (1989)

26. H. Yamashita, S. Yamaguchi, R. Nishimura, T. Maekawa, T. Okada, Anal. Sci. 17(1), 45 (2001)

27. D.H. Lindsley (ed.), Reviews in Mineralogy, Oxide Minerals: Petrologic and Magnetic Significance, vol. 25 (Mineralogical Society of America, Chelsea, 1991)

28. J.W. Anthony, R.A. Bideaux, K.W. Bladh, M.C. Nichols, Handbook of Mineralogy, Halides, Hydroxides, Oxides, vol. 3 (Mineralogical Society of America, Tuscon, 1997)

29. S. Pagès-Camagna, S. Colinart, Archaeometry 45(4), 637 (2003)

30. K.H. Butler, M.J. Bergin, V.M.B. Hannaford, J. Electrochem. Soc. 97(4), 117 (1950)

31. J. Sato, N. Saito, H. Nishiyama, Y.J. Inoue, Photochem. Photobiol. A 148, 85 (2002)

32. V.V. Zyryanov, V.G. Ponomareva, G.V. Lavrova, Inorg. Mater. 42, 410 (2006)

33. Z. Zivkovic, N. Strbac, D. Grujicic, B. Boyanov, Thermochim. Acta 383, 137 (2002) 